\title{
Exploration of the Way out for Education Reform Based on the Status Quo of Chinese and Foreign Education Systems
}

\author{
Yifan Wang \\ University of Saskatchewan, Canada
}

\begin{abstract}
Against the backdrop of growing national strength and rapid economic development, the government has placed more emphasis on education. In recent years, remarkable achievements have been registered in terms of education in China, which lays a solid foundation for cultivating comprehensive professionally-trained personnel in the new era. However, the current education system is ridden with many setbacks and problems. This paper conducts an analysis of the specific conditions of education both at home and abroad, status quo of education in China, makes some reflections on the direction and measures of China's education reform based on the practical reality of education in China. Measures should be taken to inject personalities into the traditional, exam-oriented education system, which keeps pace with the new era. As is known to all, it's important to strike a balance between public education and non-government funded education in a scientific and reasonable manner. The overhauling of traditional education policies will pave the way for China's educational renaissance and realize the great blueprint of the Chinese dream.
\end{abstract}

Keywords: Chinese and foreign education systems; The way out for the reform; Non-government funded education; Private education

DOI: http://dx.doi.org/10.26549/jetm.v2i2.735

\section{Introduction}

$\mathrm{F}$ undamental differences are found in the development of Chinese and foreign education systems. Based on the setbacks and disadvantages in the status quo of China's overall education system, this paper makes an analysis of the advanced educational concepts and teaching models in foreign countries, and, proceeding from China's education reform and innovation, seeks an ideal approach suitable for the future development of education in China, thus laying a sound foundation for the successful transition from exam-oriented education to quality-oriented education.

\section{Important Indicators of Education in Different Countries across the World}

First of all, the gross enrollment rate is an important indi- cator of education in different countries across the world. The difference in gross enrollment rate between China and foreign countries is based on the following concept: some international scholars have proposed that the gross enrollment rate of higher education $20 \%-60 \%$ means that higher-education enjoys a general popularization, and the number $60 \%$ means that higher-education enjoys a comprehensive popularization. This paper, based on the data "2016 Student Enrollment Rates in Selected Countries across the World" published in 2017 International Statistical Yearbook, has selected the gross enrollment rates of higher education in eight countries (the developed countries and the medium-ranking countries included, based on the sum of the global income average) -- the United States, Germany, Thailand, Japan, Switzerland, Norway, South Korea, and China, and made a comparison (see Table 1).

Corresponding Author: Yifan Wang, juliewang1101@hotmail.com 
Table 1. Student Enrollment Rates of Primary Schools, Middle Schools, and Universities in Major Countries across the World in 2016 and in 2015 (unit: \%)

\begin{tabular}{|c|c|c|c|c|c|c|c|c|c|c|c|}
\hline Year State & $\begin{array}{c}\text { The global } \\
\text { average }\end{array}$ & $\begin{array}{c}\text { Developed } \\
\text { countries }\end{array}$ & $\begin{array}{l}\text { Medium-rank- } \\
\text { ing countries }\end{array}$ & $\begin{array}{c}\text { The United } \\
\text { States }\end{array}$ & Germany & Thailand & Japan & Switzerland & Norway & $\begin{array}{l}\text { South } \\
\text { Korea }\end{array}$ & China \\
\hline Year of 2016 & 28 & 82 & 36 & 96 & 64 & 57 & 65 & 85 & 66 & 102 & 30 \\
\hline Year of 2015 & 15 & 60 & 18 & 64 & 55 & 52 & 59 & 70 & 54 & 82 & 12 \\
\hline Growth rate & +9 & +19 & +15 & +25 & +6 & +4 & +13 & +18 & +11 & +25 & +20 \\
\hline
\end{tabular}

Seen from that, China, with its gross enrollment rate of universities and colleges growing at a fast rate, has been recognized as one of the medium-ranking countries across the world. According to the strategic plan on the longterm education reform and development formulated by the state, by 2020, the gross enrollment rate of higher education in China will reach $60 \%$. Notwithstanding a certain distance from that of the developed countries, education in China enjoys a bright prospect with numerous untapped potential. Benefiting from the high-education popularization in its infancy, we have every confidence in the comprehensive popularization of higher education in the future. In addition, besides the gross enrollment rate, the level of education serves as another significant indicator of the education development. ${ }^{[1]}$ The level of education depends on the scientific research of universities and colleges (for short, the research). For each country, the scientific research of universities and colleges has its own cultural characteristics and academic basis. It exerts a direct impact on science and technologies of the country, and carries significant implications for the country's international status in the world's academic fields of science and technologies.

\section{Differences in the Education Development at Different Stages both at Home and Abroad}

The essential differences between Chinese and foreign education systems are mainly reflected in the people's insights into the education, as well as educational concepts. In Western countries, attention is paid to the related data on the education system, and the practical development of education. However, the development of education in our country is relatively conservative, compared to that of Western countries. In China, as for the educational concept, more emphasis is placed on critical thinking and perception, which is not the case in Western countries. Based on the practical issues of education in China, a solution which is fairly scientific and reasonable has been proposed. The details are as follows.

\subsection{Differences in the Primary Education Develop- ment both at Home and Abroad}

The primary education in China is clean different from that in foreign countries. Primary education, as an initial stage of life-time education, plays an important role in establishing the outlook on life and values in the future. ${ }^{[2]}$ As for the primary education in China, the classroom-education model, traditional as it is, is still adopted. Under this model, students, confined into the classrooms, are infused with theoretical knowledge from the texts. The personalities and characteristics of students are ignored, and little emphasis is placed on extracurricular activities and knowledge on popular science. As a result, students do a bad job in combining theoretical knowledge with practical activities, and the concept of exam-oriented education remains prevalent. However, the primary education in foreign countries focuses on personalities and self-liberation of students. Based on the innocent characteristics of students, a large number of extra-curricular activities and lessons on popular science are coordinated, in order to create a supportive environment in which students fully engage with the nature. In foreign countries, the in-class time is relatively short, compared with that in China. Various measures are taken, for instance, the combination of education and multi-media games, thus encouraging students to actively engage in the boring programs of textbook education. As a result, students, with their stimulated interest in learning, make progress in their academic performance. ${ }^{[3]}$

\subsection{Differences in the High-School Education Devel- opment both at Home and Abroad}

There are differences in the high-school education development in various provinces and counties in China. As a result, this has brought different effects to the educational concepts. At the high-school education stage, students liberate themselves and release their vitalities. Most high schools provide students with a variety of extracurricular activities and lessons. By means of the traditional classroom-education model, the academic performance of students gradually improves, thus laying a foundation for various exams and making a full preparation for the college entrance examination. However, the high-school education in foreign countries is more tedious and strict, compared with that in China. For example, in the United States, high-school education focuses on cultivating comprehensive professionally-trained personnel. A student should do well in both academic performance and various sports activities. Besides, more emphasis is put on art lessons and extra-curricular activities. The enrollment 
standard of students' academic performance is extremely demanding, and the factors of art and sports are also taken into consideration. In addition, foreign students must pass the TOEFL exam. The pressure imposed on students in foreign countries far exceeds that imposed on students in China.

\subsection{Differences in the University Education Devel- opment both at Home and Abroad}

At the university stage, students get academically accomplished. Those who have got through the strict selection of the college entrance examinations are entitled to start their univesity education. China's universities adopt traditional strategy of "strict standard of enrollment and easy access to graduation". Thus, students feel that once they step into universities, they relaxed physically and mentally, will get free from any burden, and engage in various programs of higher education, resulting in neglecting and lag behind of their professional courses and studies. Students, who have been infused with traditional in-class theoretical knowledge, do a bad job in self-learning, with no wide expansion of thinking abilities and cognitive competence. They are ridden with a lack of ideas of innovation. ${ }^{[4]}$ The higher standard the education is, the more difficult it is to keep pace with its counterpart abroad. Therefore, the education of undergraduate study and professional training develops side by side with its counterpart abroad. As for the postgraduate education, there are many disadvantages, which ultimately results in the overall decline of the quality of doctoral education and the lack of originality and adaptability for talent cultivating. This poses great threat to the future development of students. However, foreign universities attach importance to students' self-discipline, self-learning and self-guidance. Students often complete their studies through self-learning, and professors merely perform the tasks of issue-solving and summarizing. In addition, foreign universities place emphasis on the social practice which students engage in. Students, specifically trained according to their characteristics, are equipped with capabilities of adapting themselves to the social development.

\section{Better Meet the Educational Needs of People}

\subsection{Importance of Equal Emphasis on the Balance and Equalization of Education}

First, the reform of China's education development should proceed from the balance and equalization of education. It cannot be avoided that education fairness is not only a daunting issue in China's education development, but also a heated focus in the international education community. Effective measures and countermeasures should be taken to solve the issue. In this connection, this paper, based on the practical reality of different countries, makes an analysis. In China, the education system is relatively simple, and the educational concepts are traditional. Thus, advantages and fixities are mixed with shortcomings and setbacks. To establish a system of balanced education, first, it is necessary for the government to clarify its responsibilities. The government, as an entity in charge of both the rule of the state and the people's livelihood, should speed up its efforts in educational equalization. ${ }^{[5]}$ The government should take the education-related issues as the top priority of its overall strategies, direct more funds to the undertakings of education, and vigorously engage in the construction and maintenance of educational infrastructure. Besides, it should make uniform standards on tuition fees, and make unrelenting efforts to ensure that children have easy access to education opportunities. What's more, it should eliminate privilege-oriented misconducts, and meet the education needs of people from all walks of life. Last but not least, it should, by means of various funds used for education programs, give more support to low-income groups, and ensure them access to complete service of education. However, in foreign countries, the strategy of public education is often employed to solve the issue -- the equalization of education. The per capita living standard in foreign countries is generally higher, and the educational concepts are different from those in China. The public education enjoys a higher rate of popularization in foreign countries, and the higher education is basically the same as the compulsory education in China. The comprehensive coverage of public education has promoted the equalization of education in most regions. Some affluent citizens have access to the resources of privately-funded institutions. In terms of the quality of education, privately-run schools are far better than public education institution. Certain differentiated groups choose to learn in privately-run schools. Therefore, the goal -- the equalization of education has been attained.

\subsection{Take Bold Steps for Education Reform and In- novation}

In this diversified world, people's needs are multifarious. Thus, the education reform, which is systematic and scientific, should be carried out in two aspects. Firstly, the traditional enrollment system should be reformed. ${ }^{[6]}$ Universities and colleges should be given more autonomy in the standards of admission. For instance, they, in light of their actual conditions, are able to enroll students in an independent manner. Universities and colleges have its characteristic campus culture and learning atmosphere. Therefore, different standards should be laid down for personnel training. National education institution should, based on this, make some breakthroughs in allowing uni- 
versities and colleges to formulate standards of admission independently, in accordance with the national programs of school running and personnel training. Currently, the Ministry of Education has set up pilots in many key universities and colleges, and yielded fruitful results. It should be suggested that the "211" and "985" universities and colleges should work towards the same direction with those universities and colleges with their emphasis on training of practical talents, and at the same time, the policies of independent enrollment should be carried out on the ground. After a relatively long period of efforts and trials, the enrollment reform of universities and colleges has stimulated the reform of primary and secondary schools, thus accelerating the transition from exam-oriented education to quality education. Thus, a relatively scientific education system, characterized by the integration of educational concepts of the highest standards across the world, has been established in China. Secondly, the reforms targeted at non-governmental education institutions should be launched. We should vigorously develop private education. Nowadays, we should discard old-fashioned ideas. We must reject the traditional mindset (single-minded as it is) that non-government private education merely pursues economic returns, rather than high standards of teaching. We should not impose restrictions on it. A sound education system should create a supportive environment in which private education and public education coexist in harmony, and work towards the same direction. Under the macro-control of national education institution, we should strengthen our efforts in non-government private education, and some substantive policies should be laid down to give more autonomy and equality rights to privately-funded schools. An equal environment should be created in which privately-funded schools will improve their competence in education infrastructure and teachers training, with the comprehensive enhancement in both hardware and software. As a result, public education institution and private education institution will be mutually supplemented, thus paving the way for the all-round development of education in China. ${ }^{[7]}$

\section{The Historical Status Quo and Future Develop- ment of Non-Government Funded Education in China}

\subsection{The Historical Evolution of Early Non-Govern- ment Funded Education in China}

The early non-government funded education in China dates back to the modern era, and the emergence of the earliest universities in China is attributed to private education. Thus, it shows that in China private universities have a much longer history than their publicly-run counterparts.
In the early years after the founding of PRC, there were as many as 68 private universities in China, including Fudan University, Nankai University, Kwang Hua University, and so on. These universities and colleges were wellknown in the country and even across the world. They, as private education institutions, although run by individuals or private groups, prided themselves upon profound scholarship and campus abundance. The principals of non-government universities were all reputed scholars and educators in the country. After 1952, according to the related policies issued by the state, universities and colleges were consolidated and overhauled, and privately-run higher-education institutions were transformed into public institutions. From then on, for a long period, private schools and non-government funded education could not be found in China. When Cultural Revolution was put to an end in 1978, thanks to the restoration of the institution of college entrance examination, various training courses targeted at exam-oriented education found their way throughout the country. After several years of rapid development, non-public education institutions achieve vigorous growth, thus indicating that China has embarked on a new journey of private education. In the early years of the 21 st century, China has increased its support for non-government private education institution, and established the basic principle of public education institution as the core, and non-government funded education institution as a supplement". Thus, these two types of schools complement each other. This strategic idea of "walking on two legs towards the same direction" has brought the advantages of private education into full play, and promoted the sound development of private education. ${ }^{[8]}$

\subsection{The Status Quo and Future Development of Non-Government Funded Education in China}

First of all, at this stage, non-government funded education is in its prime - all flowers bloom together, and a hundred schools of thought contend. Non-government funded education, once ridden with such problems as backward educational infrastructure, limited space of education, and low quality of teaching resources, has remarkably improved its competence in recent years. Benefiting from the enhancement of its comprehensive strength, private education has attracted the attention of people from all walks of life. Nowadays, the traditional educational concept, exam-oriented as it is, has been discarded, and diversified educational institutions have been established, thus meeting the needs of different consumers. Therefore, status quo of non-government funded education has maintained a sound momentum, and great progress has been registered in terms of integrating educational resources, expanding the scale of education, attracting economic 
investment, energizing the school-running ideas, and serving the well-fare of people. Some non-governmental funded universities and colleges have become the focus of postgraduate training, which has an important positive significance for the success of non-government funded education. In addition, non-governmental funded private education in our country enjoys untapped potential in the future. Currently, across the world, more emphasis is placed on private education, instead of public education. Private education has such benefits as a higher level of freedom and more autonomy over its counterpart. It, in terms of the establishment of academic subjects and the expansion of profound scholarship, focuses on personalities and interests of students. In the future, the education system in China shows a trend of diversification, colorful abundance, and scientific application in multiple areas. We should renew our efforts in the reform of non-government funded education, and eliminate its setbacks and retain its advantages, thus strengthening the control over non-government funded private education. In the future, non-government private education and public education, complemented with each other, should work towards the same direction in an ambience of free education, thus taking credits for the development of education in China.

\section{Conclusion}

Boosting the nation through science and education is a fundamental task crucial for generations to come. Since the reform program and opening-up, great achievement has been registered in China's education. By means of the analysis and comparison of the status quo of Chinese and foreign education systems, the problems and setbacks of China's education system, which should be addressed, are clearly identified. Therefore, we should, by means of scientific and rational methods, proceed from the practical reality of China's education system, and draw lessons from its foreign counterpart. We should take bold steps for education reform and innovation, thus drawing a blueprint for national rejuvenation through science and education, as well as a prosperous country and the well-being of people.

\section{References}

[1] Teng Huang. Exploration of the Way Out for Education Reform Based on the Status Quo of Chinese and Foreign Education Systems[J]. World Education Information, 2017, 8(21): 10-16. (in Chinese)

[2] Yachen Yan, Weixian Wang. Exploration of the Way Out of Enterprise-run Education Reform[J]. CFHI Technology, 2016, 8(5): 55-56. (in Chinese)

[3] Xuhui Song, Zhaoxiang Luan. What's the Way Out for Deepening the Education Reform? -- Reflections on the Strategy of "Separation of Schools and Enterprises" Formulated by the Bureau of Education, Nanshi District[J]. Shanghai Education, 2017, 14(7): 7-8. (in Chinese)

[4] Xianze Lu. What's the Way Out for China's Elementary Education? -- Afterthoughts on Education for Free Breath by Xigui Li[J]. Chinese Teacher, 2016, 6(7): 43-44. (in Chinese)

[5] Zhenfang Zhang. Returning Freedom to Education -- Afterthoughts on Education for Free Breath by Xigui Li[J]. Jiangxi Education, 2016, 15(29): 6-8. (in Chinese)

[6] Jitang Yang. The New Exploration and Reflection of Vocational Education Launched by State-owned Enterprises under the New Circumstances of Vocational Education Reform -- Taking Wuhan Maritime Institute as an Example[J]. Survey of Education (Ten-day Journal), 2017, 2(11): 6-7. (in Chinese)

[7] Ning Ding. The Status Quo of Family Education and Its Way Out[J]. Academy: Scholar's Spiritual Homeland and Teaching of Free Soil, 2016, 12(5): 150-151. (in Chinese)

[8] Junying Hao. The Status Quo, Dilemma and Way Out of China's Community Education[J]. Research and Strategies on the Development of China's Adult Education, 2017, 3(17): 150-152. (in Chinese) 